provides the most practicable and economic method of preventing accelerated erosion".

There are many parts of the British Empire where erosion in one form or another is becoming an everincreasing danger to the means of livelihood of the populations, as is the case, for example, in large parts of Africa. The above remarks of the Director on a suggested method of control may be commended to the administrations concerned; in fact, the whole report-a war-time report-would repay a careful study by all having administrative responsibilities in connexion with the land and its well-being throughout the Empire.

\section{MODERN DEVICES CONTROLLING ELECTRICAL CIRCUITS}

A PROGRESS review on "Circuit-controlling Devices on Power Supply Systems" has been given by C. W. Marshall (J. Inst. Elect. Eng., 89, Pt. 1 ; April, 1942). The review commences with a summary of the technical aspects of power circuit control, considered in three main sections : limitation of current amplitude, limitation of voltage, and making and breaking of circuits.

The paper then proceeds to illustrate what has actually been accomplished by reference to outstanding features of switchgear construction. Illustrated examples are given of a $0 \cdot 4-\mathrm{kv}$., 600 -amp. air circuit-breaker, a 0.4-kv., three-phase, 800-amp. rating, switchboard, an 11-kv., 750 Mva. metal-clad circuit-breaker, a five-panel assembly of $11-\mathrm{kv}$., 500 Mva., metal-clad switchgear with circuit-breakers of: the draw-down type; the latter are fitted with arc-control devices. A pictorial sectional view of a modern switching unit is given, and shows inter alia the circuit-breaker, the means of connecting it to the busbars and to the outgoing circuit, and also the disposition of the current and voltage transformers.

A 33-kv. metal-clad switchgear is depicted, the busbar chambers in this case being filled with 'Freon' gas, and fitted with removable circuit-breakers. A third type of $33-\mathrm{kv}$. metal-clad switchgear is shown in which small oil-content type circuit-breakers are arranged horizontally. Two other small oil-content breakers are illustrated, one being an electrically operated type with a horizontal breaker, while the other has a vertically mounted breaker operated by compressed air. The last example of $33-\mathrm{kv}$. practice shows one of the most advanced and interesting designs which is available for commercial application. The general busbar structure follows standard metalclad practice. The circuit-breaker, however, is of the air-blast type and this development is believed to be unique.

Two examples of $66 \mathrm{kv}$. switchgear are shown, the first being of the vertical type with double busbars and oil-immersed busbar selectors, while the second is a single-break, small-oil-volume, porcelain-clad unit. A group of $132-\mathrm{kv}$. units is shown, including a large-oil-volume circuit-breaker originally fitted with four open breaks and converted to a double-break type with arc control. Another illustrates the transition from the large-oil-volume circuit-breaker with steel tanks to the small-oil-volume, porcelain-clad type. A cross-sectional view illustrates all the essential parts of one phase of the breaker, and a photograph shows the complete assembly of a three-phase unit and offers a good idea of its size.
The practical performance of the various classes of installation is assessed, short-circuit test performance figures are given for typical circuit-breakers, mention is made of the test performance of modern fuses, and a tribute is paid to the remarkable efficiency of the various short-circuit testing stations. The period reviewed has been remarkable for the advance in knowledge of the intimate phenomena of arc rupture due to the fundamental research work of the British Electrical and Allied Industries Research Association, supplemented by the development work done in the various British switchgear testing stations.

\section{A.R.P. AND THE ENGINEERING INDUSTRY}

A CONFERENCE on air-raid precautions and the engineering industry arranged by the Institutions of Electrical, Civil and Mechanical Engineers with the co-operation of the Ministry of Home Security (Research and Experiments Department) was held at the Central Hall, Westminster, on December 9, and summaries of the three addresses delivered are contained in the Journal of the Institution of Electrical Engineers (89, Pt. I, April, 1942).

In an address on the "Effect of High Explosives on Structures", Prof. J. D. Bernal said that the main effects of explosions were covered by describing the arrival of the bomb or mine, and then the three chief mechanisms by which mines and bombs cause damage: blast; bomb fragments; earth shock when a bomb explodes in the ground. The distance a bomb travels before exploding is of more importance than the distance of penetration. This is determined not by the penetrating power but by the kind of fuse it carries. The distribution of fragments from a bomb exploding in air was explained to consist of three zones: those shot off at right angles to the side of the bomb, forming the main fragment zone; tail fragments, usually light; and nose fragments, usually heavy. The simple physics of the released gases was explained in connexion with peak blast pressure. An analysis was given of the reactions of a structure to blast, mention being made of the fact that resonance can be a contributory cause to damage if the half-period of the structure is of the same order as the time-interval between maximum pressure and maximum suction. The effects of shock waves from bombs exploding subterraneously were also described.

Prof. J. F. Baker dealt with the "Design of Protective Structures and the Defence of Industry" in an address which described principles of structural design for protecting industry from air attack which, though unfamiliar in normal engineering practice, can claim recognition as rational. Effective resistance was explained to be achieved by resistance accompanied by provision against failure by shear, while ductility in material and continuity in structural form combined with mass are essential if the structure takes the form of a wall. Recommendations were made for the protection of workers by shelters, and suggestions made as to a rationalized system of structural design for strengthening floors to carry loading by debris and for stability under earth shock. The criterion of proper protection was stated to be such that, having regard to war hazards, the total probable output over a period of all existing factories 